\title{
Regional perinatal mortality differences in the Netherlands; care is the question
}

\author{
Miranda Tromp*1, Martine Eskes ${ }^{1}$, Johannes B Reitsma2 ${ }^{2}$ Jan Jaap \\ HM Erwich ${ }^{3}$, Hens AA Brouwers ${ }^{4}$, Greta C Rijninks-van Driel ${ }^{5}$, \\ Gouke J Bonsel ${ }^{6}$ and Anita CJ Ravelli ${ }^{1}$
}

Address: ${ }^{1}$ Department of Medical Informatics, Academic Medical Center, University of Amsterdam, Amsterdam, the Netherlands, ${ }^{2}$ Department of Clinical Epidemiology, Biostatistics and Bioinformatics, Academic Medical Center, University of Amsterdam, Amsterdam, the Netherlands, ${ }^{3}$ Department of Obstetrics and Gynaecology, University Medical Center Groningen, Groningen, the Netherlands, ${ }^{4}$ Department of Neonatology, University Medical Center Utrecht, Utrecht, the Netherlands, ${ }^{5}$ Department of Obstetrics and Gynaecology, Academic Medical Centre, Amsterdam, the Netherlands and 'Department of Health Policy and Management, Erasmus Medical Center, Rotterdam, the Netherlands

Email: Miranda Tromp* - m.tromp@amc.uva.nl; Martine Eskes - m.eskes@amc.uva.nl; Johannes B Reitsma - j.reitsma@amc.uva.nl; Jan Jaap HM Erwich - j.j.h.m.erwich@og.umcg.nl; Hens AA Brouwers - h.a.a.brouwers@umcutrecht.nl; Greta C Rijninks-van Driel - g.c.rijninksvanDriel@amc.uva.nl; Gouke J Bonsel - g.j.bonsel@erasmusmc.nl; Anita CJ Ravelli - a.c.ravelli@amc.uva.nl

* Corresponding author

Published: 14 April 2009

BMC Public Health 2009, 9:102 doi:10.1 186/147/-2458-9-102
Received: 23 September 2008

Accepted: 14 April 2009

This article is available from: http://www.biomedcentral.com/I47I-2458/9//02

(c) 2009 Tromp et al; licensee BioMed Central Ltd.

This is an Open Access article distributed under the terms of the Creative Commons Attribution License (http://creativecommons.org/licenses/by/2.0), which permits unrestricted use, distribution, and reproduction in any medium, provided the original work is properly cited.

\begin{abstract}
Background: Perinatal mortality is an important indicator of health. European comparisons of perinatal mortality show an unfavourable position for the Netherlands. Our objective was to study regional variation in perinatal mortality within the Netherlands and to identify possible explanatory factors for the found differences.

Methods: Our study population comprised of all singleton births $(904,003)$ derived from the Netherlands Perinatal Registry for the period 2000-2004. Perinatal mortality including stillbirth from $22^{+0}$ weeks gestation and early neonatal death (0-6 days) was our main outcome measure. Differences in perinatal mortality were calculated between 4 distinct geographical regions NorthEast-South-West. We tried to explain regional differences by adjustment for the demographic factors maternal age, parity and ethnicity and by socio-economic status and urbanisation degree using logistic modelling. In addition, regional differences in mode of delivery and risk selection were analysed as health care factors. Finally, perinatal mortality was analysed among five distinct clinical risk groups based on the mediating risk factors gestational age and congenital anomalies.

Results: Overall perinatal mortality was 10.1 per I,000 total births over the period 2000-2004. Perinatal mortality was elevated in the northern region (II.2 per I,000 total births). Perinatal mortality in the eastern, western and southern region was I0.2, 10.1 and 9.6 per I,000 total births respectively. Adjustment for demographic factors increased the perinatal mortality risk in the northern region (odds ratio $1.20,95 \% \mathrm{Cl} 1.12-1.28$, compared to reference western region), subsequent adjustment for socioeconomic status and urbanisation explained a small part of the elevated risk (odds ratio I.II, $95 \% \mathrm{Cl}$ I.03-1.20). Risk group analysis showed that regional differences were absent among very preterm births $\left(22^{+0}-25^{+6}\right.$ weeks gestation) and most prominent among births from $32^{+0}$ gestation weeks onwards and among children with severe congenital anomalies. Among term births $\left(\geq 37^{+0}\right.$ weeks) regional mortality differences were largest for births in women transferred from low to high risk during delivery.
\end{abstract}

Conclusion: Regional differences in perinatal mortality exist in the Netherlands. These differences could not be explained by demographic or socio-economic factors, however clinical risk group analysis showed indications for a role of health care factors. 


\section{Background}

Perinatal mortality is an important indicator of health and the quality of health care [1]. Countries or regions are often compared using perinatal mortality rate. The position of the Netherlands in international comparative research is unfavourable. In 2003 the results of the PERISTAT study showed that Dutch perinatal mortality for the year 1999 was substantially higher compared to other European countries (stillbirth rate of 7.4 per 1,000 total births and early neonatal mortality of 3.5 per 1,000 live births) $[1,2]$.

The observed differences in perinatal mortality across Europe are difficult to explain unequivocally because of the many potential explanations like variation in registration practices, differences in definitions, and variation in demographic structure [3]. On the national level, fair comparisons can be achieved more easily. Dutch public health policies aim to reduce national health inequalities if existent [4]. It is unknown whether the current Dutch perinatal mortality is uniformly distributed across the country; differences have been reported based on civil data in the early eighties $[5,6]$. Although the Netherlands is a small country, regional variation exists in the degree of urbanisation, the number of immigrants and to a lesser extent, in socio-economic status. Regional variation in mortality from other causes like cardio-vascular diseases and cancer has been reported before [7-9].

Factors related to regional differences in perinatal outcome reported in other European countries after adjustment for demographic factors, include population density [10], access and use of health services [11], income level and social inequality $[12,13]$ and excess risk for certain conditions [14].

The objective of this study is to examine whether regional differences in perinatal mortality in the Netherlands exist for the period 2000-2004, and whether these differences persist after taking into account various risk factors that have been linked to regional variation in perinatal mortality.

\section{Methods \\ Data source}

Data from the Netherlands Perinatal Registry (PRN) 2000-2004 were used. The PRN is a database that contains the linked data from three registries: the national obstetric database by midwives (LVR-1 registry), the national obstetric database by gynaecologists (LVR-2 registry) and the national neonatal/paediatric database (LNR registry) [15]. The PRN registry contains comprehensive data on pregnancy, provided care (interventions, referrals) and pregnancy outcomes [16]. The coverage of the PRN is about $96 \%$ of all deliveries in the Netherlands. All variables are recorded by the caregiver during prenatal care, delivery and neonatal, lying-in period. The data are annually sent to the national registry office, where a number of range and consistency checks are conducted. Data on socio-economic status (SES) on the postal code level was obtained from The Netherlands Institute for Social Research (SCP).

\section{Study population}

The population for this study consisted of all singleton births born between 2000 and 2004 from 22.0 gestational weeks onwards. Gestational age was based on ultrasound or last menstrual period. If gestational age was unknown, children with a birth weight below 500 grams were excluded in accordance with the World Health Organization reporting criteria [17].

\section{Outcome measures}

Perinatal mortality was our primary outcome measure. Perinatal mortality is defined as the sum of stillbirth $(\geq$ 22.0 gestational weeks) and early neonatal mortality (deaths of live born children during the first week of life). Stillbirth rate and perinatal mortality rate were both calculated per 1,000 total births. Early neonatal mortality was calculated per 1,000 live births. Apart from mortality, the following mediating outcome measures were also analysed: preterm delivery ( $<32.0$ weeks gestational age), low birth weight (<1500 gram) and low APGAR score after five minutes (APGAR score $<4$ ).

\section{Provinces and regions in the Netherlands}

Regional differences in perinatal mortality were analysed on a province level and on a regional level. The Netherlands is formally divided into 12 provinces (see Figure 1), which form regional administrative units in between municipalities and the national government. The provinces were grouped into 4 regions based on their geographical position: Northern region (Groningen, Friesland, Drenthe), eastern region (Overijssel, Gelderland, Flevoland), western region (Utrecht, Noord-Holland, Zuid-Holland) and southern region (Zeeland, Noord-Brabant, Limburg). The northern region is the most rural area in the Netherlands, while the western region is most urbanised (the 4 largest cities are displayed in figure 1). The province of each woman was based on her registered postal code ( 4 digits) in the registry. Women with an unknown or invalid postal code $(0.2 \%)$ were removed from the analyses.

\section{Population characteristics}

Demographic characteristics of included women were compared across regions including maternal age, parity and ethnicity. Maternal age was categorised into $<20$ years, 20-34 years and $\geq 35$ years. Parity was categorised into 0 (first birth), 1 (second birth) and $2+$ (third or 


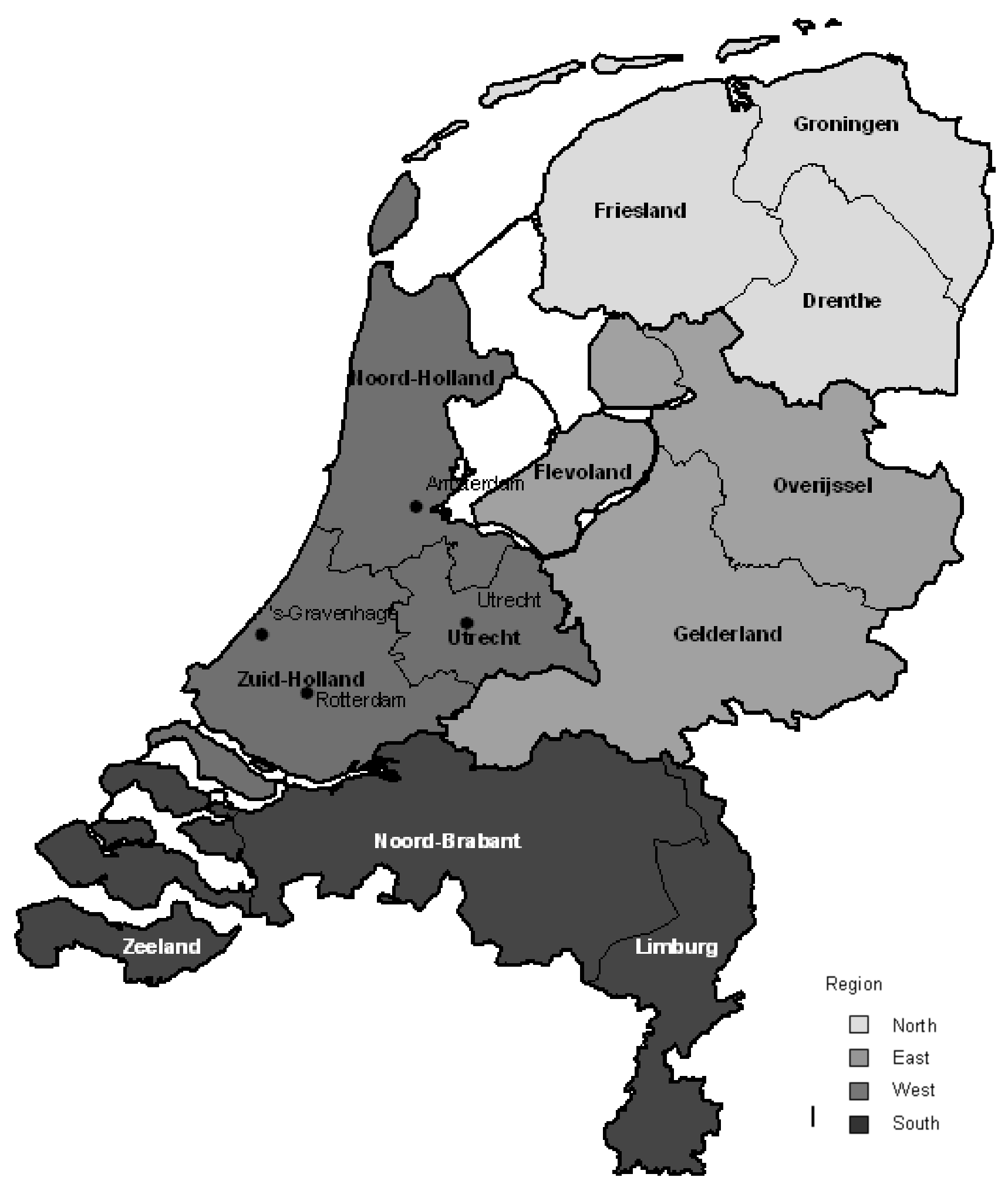

Figure I

Provinces and regions in the Netherlands. 
higher birth). Ethnicity is ascribed by the woman's care provider. For this study, we differentiated between Western (native Dutch and other Westerners) and non-Western (including different ethnic groups like African/ Surinamese Creole, Surinamese Hindustani, Moroccan and Turkish).

In addition, data on socio-economic status (SES) were obtained from The Netherlands Institute for Social Research/SCP on postal code level. Using the woman's postal code ( 4 digits) these data could be linked to the perinatal registry file. The SES score is based on mean income level, the percentage of households with a low income, the percentage of inhabitants without a paid job and the percentage of households with on average a low education in a postal code area [18]. The continuous SES score was for our purpose categorised into a high, middle and low group based on percentile ranges $\left(\leq 25^{\text {th }}\right.$ percentile, middle, $>75^{\text {th }}$ percentile). The data on socio-economic status were available for the year 2002. The categorised score was applied to the total population for the period 2000-2004 as large changes in SES score for a postal code area within two years are unlikely. By using the same postal code we could add the degree of urbanisation (number of addresses per square kilometre), a number which is routinely available. The degree of urbanisation was categorised into three groups: very rural, rural to urban and very urbanised.

\section{Clinical characteristics}

Besides population characteristics, we analysed regional variation in health care services. We geographically compared the mode of delivery and risk selection at start of delivery. Risk selection is an important feature of the Dutch obstetric system [19]. Healthy women with an uncomplicated obstetric history and/or pregnancy remain under the care of the primary level midwife and are selected as at low risk at start of delivery. In that case a woman can choose to deliver at home or at the hospital, both under supervision of the midwife. If complications occur the woman is selected as high risk and is referred to an obstetrician at the secondary or tertiary level. We analysed the risk selection status at the start of delivery.

\section{Statistical analysis}

Differences in adverse outcomes by region and province were tested by Chi-Square test using all other regions/ provinces as the reference category. Differences in population characteristics by region were tested by Chi-Square test. After describing crude mortality, logistic regression modelling was used to estimate differences in perinatal mortality between regions after adjustment for sociodemographic factors. All previously described factors were added to the model in two successive steps. First we adjusted only for demographic factors parity, maternal age and ethnicity, parity and maternal age were included as categorical variables with the category with the lowest mortality risk as reference. In the second model we additionally adjusted for the degree of urbanisation and SES. In both models we included the year of registration to incorporate changes in perinatal mortality over time. The strength of the association between potential predictors and perinatal mortality are expressed as odds ratios (OR) with $95 \%$ confidence intervals (CI).

For further interpretation of possible regional differences in perinatal mortality, the perinatal mortality risk for five clinical relevant risk groups was examined by region. These groups represent distinct clinical entities with different patterns of care based on mediating risk factors gestational age and severe congenital anomalies. Severe congenital anomalies were defined as anomalies which are either highly fatal or as anomalies potentially detectable by ultrasound and severe enough for optional late termination of pregnancy. The five groups are very preterm births $\left(22^{+0}-25^{+6}\right.$ weeks), severe congenital anomalies, preterm births $\left(26^{+0}-31^{+6}\right.$ weeks $)$ without severe congenital anomalies, preterm births $\left(32^{+0}-36^{+6}\right.$ weeks $)$ without severe congenital anomalies and term births $\left(\geq 37^{+0}\right.$ weeks) without severe congenital anomalies.

All analyses were performed using SAS for Windows (version 9.1, SAS Institute Inc., Cary, NC, USA).

\section{Results}

During the period 2000-2004, there were 904,003 singletons births in the Netherlands. Nearly half of all births were in the urbanised western region (46.1\%) and only $9.7 \%$ in the northern more rural region (see table 1 ). The overall perinatal mortality in the Netherlands in the period 2000-2004 was 10.1 per 1,000 total births. The northern region has the highest perinatal mortality rate with 11.5 and 11.9 per 1,000 total births in provinces Groningen and Friesland respectively. The southern region had the lowest perinatal mortality rate, with lowest rates in provinces Noord-Brabant and Limburg: 9.5 and 9.4 per 1,000 total births. The perinatal mortality rate in the northern region was significantly higher than in the other regions (Chi-square p-value $<0.01$ ). Both stillbirth and early neonatal mortality were high in the northern provinces. The proportion of preterm births and children with a low birth weight was also significantly higher in the northern region (1.2\% and $1.2 \%$ respectively).

The northern region had the largest proportion of women from rural areas $(41.8 \%)$ and with a low SES score $(38.0 \%)$ and the lowest proportion of non-western women $(7.2 \%)$ (Table 2$)$. The western region had the highest proportion of women aged above 35 years $(20.6 \%)$, with non-western ethnicity $(22.7 \%)$, with a high 
Table I: Adverse outcomes by region and province for singletons in the period 2000-2004.

\begin{tabular}{|c|c|c|c|c|c|c|c|c|}
\hline \multirow[t]{2}{*}{ Region/Province } & \multicolumn{2}{|l|}{$\begin{array}{l}\text { Total } \\
\text { number } \\
\text { of children }\end{array}$} & \multirow{2}{*}{$\begin{array}{r}\text { Perinatal } \\
\text { mortality } \\
\geq 22+0 \text { wks }-6 \text { d } \\
\% 。\end{array}$} & \multirow{2}{*}{$\begin{array}{r}\text { Still birth } \\
\geq 22^{+0} \text { wks } \\
\%\end{array}$} & \multirow{2}{*}{$\begin{array}{r}\text { Early } \\
\text { neonatal } \\
\text { mortality } \\
(0-6 \text { d) } \\
\%\end{array}$} & \multirow{2}{*}{$\begin{array}{r}\text { Preterm } \\
\text { birth } \\
<32^{+0} \text { wks } \\
\%\end{array}$} & \multirow{2}{*}{$\begin{array}{r}\text { Low } \\
\text { birth } \\
\text { weight } \\
<1500 \text { gram } \\
\%\end{array}$} & \multirow[t]{2}{*}{$\begin{array}{r}\text { Low } \\
\text { APGAR } \\
\text { score }<4 \\
\%\end{array}$} \\
\hline & \# & $\%$ & & & & & & \\
\hline \multicolumn{9}{|l|}{ Region } \\
\hline North (N) & 87,857 & 9.7 & $11.2^{*}$ & 7.9 & 3.3 & $1.2^{*}$ & $1.2 *$ & 0.3 \\
\hline East $(\mathrm{E})$ & 200,158 & 22.1 & 10.2 & 7.3 & 2.9 & I.I & I.I & 0.3 \\
\hline West (W) & 416,768 & 46.1 & 10.1 & 7.2 & 2.9 & I.I & I.I & 0.3 \\
\hline South (S) & 199,220 & 22.0 & $9.6^{*}$ & 6.9 & 2.7 & I.I & 1.1 & 0.3 \\
\hline \multicolumn{9}{|l|}{ Province } \\
\hline Groningen-N & 30,200 & 3.3 & 11.5 & 8.4 & 3.1 & $1.4^{*}$ & $1.4^{*}$ & 0.4 \\
\hline Friesland-N & 31,554 & 3.5 & $11.9 *$ & 8.1 & $3.9 *$ & $1.3^{*}$ & 1.3 & 0.3 \\
\hline Drenthe-N & 26,103 & 2.9 & 9.9 & 7.1 & 2.8 & I.I & 1.0 & 0.2 \\
\hline Overijssel-E & 65,980 & 7.3 & 10.2 & 7.3 & 2.8 & I.I & I.I & 0.3 \\
\hline Gelderland-E & 113,496 & 12.6 & 10.1 & 7.2 & 2.9 & I.I & I.I & 0.3 \\
\hline Flevoland-E & 20,682 & 2.3 & 10.9 & 7.9 & 3.1 & 1.2 & 1.3 & 0.3 \\
\hline Utrecht-W & 73,645 & 8.1 & 10.2 & 6.7 & $3.5^{*}$ & 1.0 & $1.0^{*}$ & 0.3 \\
\hline Noord-Holland-W & 149,009 & 16.5 & 9.8 & 7.1 & 2.8 & 1.2 & 1.1 & 0.3 \\
\hline Zuid-Holland-W & 194,114 & 21.5 & 10.3 & 7.5 & 2.8 & I.I & I.I & 0.3 \\
\hline Zeeland-S & 15,363 & 1.7 & 10.9 & 7.5 & 3.4 & 0.9 & 1.1 & 0.3 \\
\hline Noord-Brabant-S & 130,973 & 14.5 & 9.5 & 6.8 & 2.7 & I.I & I.I & 0.3 \\
\hline Limburg-S & 52,884 & 5.8 & 9.4 & 6.8 & 2.6 & 1.1 & 1.2 & 0.3 \\
\hline Total & 904,003 & 100 & 10.1 & 7.2 & 2.9 & I.I & I.I & 0.3 \\
\hline
\end{tabular}

* Significantly different $(\mathrm{p}<0.0 \mathrm{I})$ from all other regions/provinces excluding the region/province itself.

SES score (32.9\%) and living in urban areas (36.4\%). All these regional differences were statistically significant.

Table 3 shows that women from the northern region had a significantly higher perinatal mortality risk compared to the western region (unadjusted OR 1.11, 95\% CI 1.031.19). The western region was set as reference area because the perinatal mortality risk was the same as the overall rate. After adjustment for demographic factors (maternal age, parity and ethnicity), the women in the northern region (OR 1.20, 95\% CI 1.12-1.28) and eastern region (OR 1.08, 95\% CI 1.02-1.14) had a significantly higher perinatal mortality risk compared to women in the western region. Living in a very urban area and having a low

Table 2: Population characteristics by region for the period 2000-2004.

\begin{tabular}{|c|c|c|c|c|c|c|c|c|c|}
\hline & \multirow{2}{*}{$\begin{array}{r}\text { North } \\
\#\end{array}$} & \multicolumn{3}{|c|}{ East } & \multirow{2}{*}{$\begin{array}{r}\text { West } \\
\#\end{array}$} & \multicolumn{3}{|c|}{ South } & \multirow[t]{2}{*}{ Chi-Square } \\
\hline & & $\%$ & \# & $\%$ & & $\%$ & \# & $\%$ & \\
\hline Number of singleton pregnancies & 87,857 & 100 & 200,158 & 100 & 416,768 & 100 & 199,220 & 100 & \\
\hline \multicolumn{10}{|l|}{ Maternal age } \\
\hline$<20$ years & 1,805 & 2.1 & 3,258 & 1.6 & 8,179 & 2.0 & 3,344 & 1.7 & $\mathrm{P}<0.0001$ \\
\hline $20-34$ years & 71,651 & 81.6 & 161,834 & 80.9 & 322,647 & 77.4 & 162,188 & 81.4 & \\
\hline$>=35$ years & $|4,40|$ & 16.4 & 35,066 & 17.5 & 85,942 & 20.6 & 33,688 & 16.9 & \\
\hline \multicolumn{10}{|l|}{ Parity } \\
\hline Nulliparous & 40,459 & 46.1 & 89,976 & 45.0 & $197,5 \mid 4$ & 47.4 & 93,654 & 47.0 & $\mathrm{P}<0.0001$ \\
\hline Parity I & 32,160 & 36.6 & 72,213 & 36.1 & $|43,73|$ & 34.5 & 72,746 & 36.5 & \\
\hline Parity $2+$ & 15,238 & 17.3 & 37,969 & 19.0 & 75,523 & 18.1 & 32,820 & 16.5 & \\
\hline Ethnicity non-western & 6,356 & 7.2 & 20,810 & 10.4 & 94,415 & 22.7 & 23,206 & 11.6 & $\mathrm{p}<0.0001$ \\
\hline Heavy smoking & 727 & 0.8 & 1,102 & 0.6 & 1,678 & 0.4 & 1,036 & 0.5 & $\mathrm{p}<0.0001$ \\
\hline \multicolumn{10}{|l|}{ Urbanisation } \\
\hline Very urban & 6,332 & 7.2 & 6,107 & 3.1 & 152,444 & 36.6 & 10,505 & 5.3 & $\mathrm{p}<0.0001$ \\
\hline Middle & 44,806 & 51.0 & 149,537 & 74.7 & 232,546 & 55.8 & 138,893 & 69.7 & \\
\hline Very rural & 36,719 & 41.8 & 44,514 & 22.2 & 31,778 & 7.6 & 49,822 & 25.0 & \\
\hline \multicolumn{10}{|l|}{ SES } \\
\hline High & 13,175 & 15.0 & 46,103 & 23.0 & 137,766 & 33.1 & 40,413 & 20.3 & $\mathrm{P}<0.0001$ \\
\hline Middle & $4 I, 321$ & 47.0 & I I 2,929 & 56.4 & 163,727 & 39.3 & 120,345 & 60.4 & \\
\hline Low & 33,361 & 38.0 & 41,126 & 20.5 & II5,275 & 27.7 & 38,462 & 19.3 & \\
\hline
\end{tabular}


Table 3: Perinatal mortality $\left(22^{+0}\right.$ weeks -6 days) risk per region after adjustment for risk factors.

\begin{tabular}{|c|c|c|c|c|c|c|}
\hline & \multicolumn{2}{|c|}{ Unadjusted } & \multicolumn{2}{|c|}{ Adjusted Model I\# } & \multicolumn{2}{|c|}{ Adjusted Model II† } \\
\hline & OR & $95 \% \mathrm{Cl}$ & OR & $95 \% \mathrm{Cl}$ & OR & $95 \% \mathrm{Cl}$ \\
\hline \multicolumn{7}{|l|}{ Region } \\
\hline North & 1.11 & $1.03-1.19$ & 1.20 & $1.12-1.28$ & 1.11 & $1.03-1.20$ \\
\hline East & 1.01 & $0.96-1.07$ & 1.08 & $1.02-1.14$ & 1.04 & $0.98-1.10$ \\
\hline West* & 1.00 & reference & 1.00 & reference & 1.00 & reference \\
\hline South & 0.95 & $0.90-1.00$ & 1.01 & $0.95-1.06$ & 0.97 & $0.91-1.03$ \\
\hline \multicolumn{7}{|l|}{ Maternal age } \\
\hline$<20$ years & 1.68 & $1.49-1.91$ & 1.38 & $1.22-1.57$ & 1.36 & $1.20-1.54$ \\
\hline $20-34$ years & 1.00 & reference & 1.00 & reference & 1.00 & reference \\
\hline$\geq 35$ years & 1.23 & $1.17-1.30$ & 1.28 & $1.21-1.35$ & 1.29 & $1.23-1.36$ \\
\hline \multicolumn{7}{|l|}{ Parity } \\
\hline Parity 0 & 1.40 & $1.33-1.47$ & 1.42 & $1.35-1.49$ & 1.42 & $1.35-1.49$ \\
\hline Parity I & 1.00 & reference & 1.00 & reference & 1.00 & reference \\
\hline Parity 2+ & 1.44 & $1.36-1.53$ & 1.32 & $|.24-1.4|$ & 1.31 & $1.23-1.40$ \\
\hline \multicolumn{7}{|l|}{ Ethnicity } \\
\hline Western & 1.00 & reference & 1.00 & reference & 1.00 & reference \\
\hline Non-Western & 1.42 & $1.35-1.50$ & 1.43 & $1.36-1.50$ & 1.37 & $1.29-1.45$ \\
\hline \multicolumn{7}{|l|}{ Urbanization } \\
\hline Very urban & 1.10 & $1.05-1.16$ & & & 0.92 & $0.86-0.98$ \\
\hline Middle & 1.00 & reference & & & 1.00 & reference \\
\hline Very rural & 1.01 & $0.96-1.07$ & & & 1.03 & $0.98-1.10$ \\
\hline \multicolumn{7}{|l|}{ SES } \\
\hline Low & 1.23 & $1.18-1.30$ & & & 1.15 & $\mid .09-1.21$ \\
\hline Middle & 1.00 & reference & & & 1.00 & reference \\
\hline High & 0.90 & $0.85-0.95$ & & & 0.91 & $0.86-0.96$ \\
\hline
\end{tabular}

* Region west was set as reference area as the perinatal mortality rate of this region was equal to the overall rate. \# Model I was adjusted for maternal age, parity and ethnicity.

† Model II was an extension of model I with additional adjustment for degree of urbanization and SES.

SES score were significant risk factors for perinatal mortality, while a high SES score lowered the risk. Subsequent adjustment for urbanisation degree and social-economic status explained a small part of the excess risk in the northern region (OR 1.11, 95\% CI 1.03-1.20). Living in an very urban area was no longer a risk factor in adjusted model II.

The health services patterns also exhibited regional differences (Table 4). The northern region had the lowest

Table 4: Description of health care factors by region.

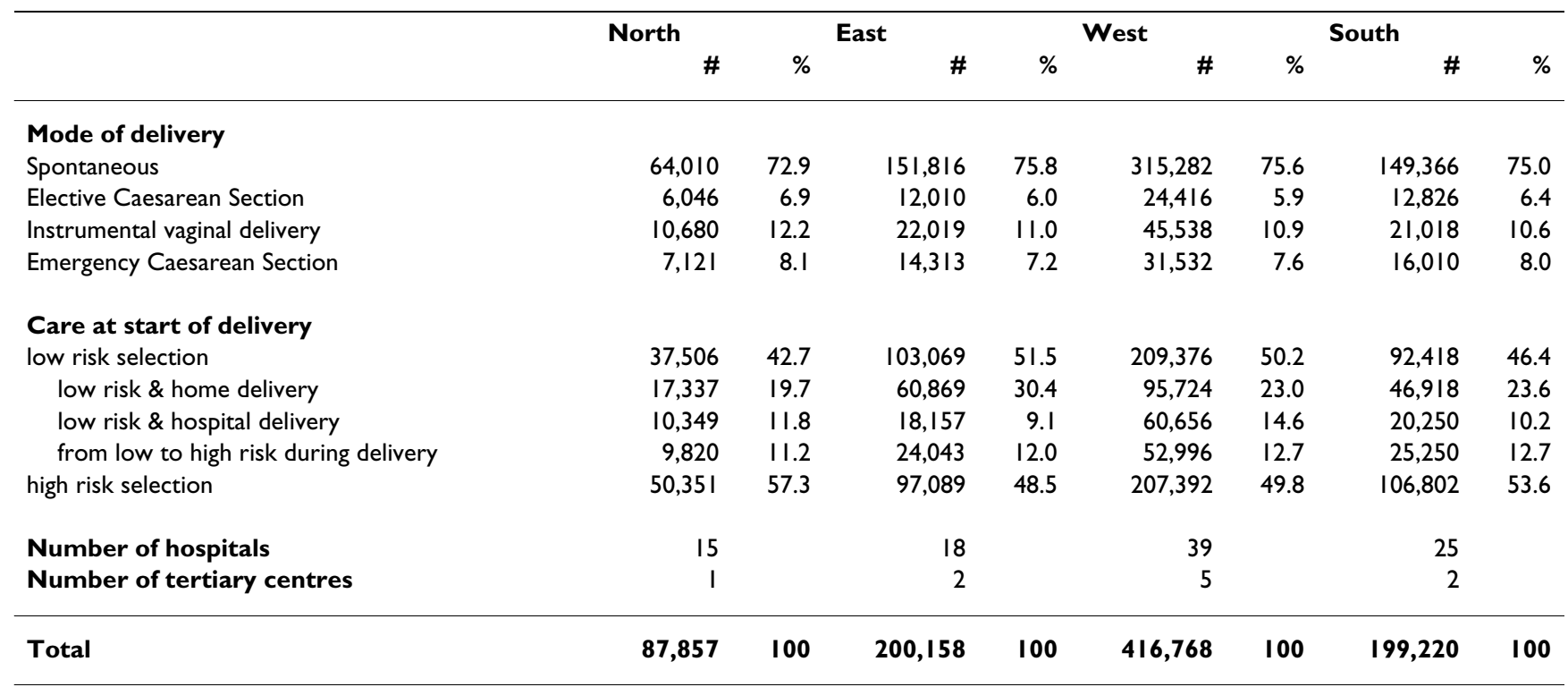


number of spontaneous deliveries $(72.9 \%$ versus $75.6 \%$ in the western region) and the lowest number of women selected as low risk at start of delivery $(42.7 \%$ versus $50.2 \%$ in the western region). The percentage of home births was $19.7 \%$ in the northern region versus $23.0 \%$ in the western region and in the eastern region the percentage of home births was as high as $30.4 \%$. There were only small variations in the percentage of women transferred from low risk to high risk during delivery $(11.2 \%$ in the northern region and $12.7 \%$ in the western region). In the northern region most deliveries take place under supervision of an obstetrician (57\%). The northern region has the lowest number of hospitals and only 1 tertiary hospital.

Among very preterm births (responsible for $28 \%$ of all perinatal deaths), the perinatal mortality risk was about the same in all regions (Table 5). The perinatal mortality risk for children with severe congenital anomalies (responsible for $12 \%$ of perinatal deaths) was higher in the northern region (204 per 1,000 births) compared to the western region $(147$ per 1,000$)$. The mortality risk among preterm births $26^{+0}-31^{+6}$ weeks (responsible for $14 \%$ of perinatal deaths) in the northern region was lower than in the western region (233 versus 237 per 1,000). The mortality risk among preterm births $32^{+0}-36^{+6}$ weeks (responsible for $18 \%$ of perinatal deaths) was higher in the northern region and lower in the southern region than in the western region. For the term births (responsible for $28 \%$ of all perinatal deaths) the mortality risk was about $11 \%$ higher in the northern region compared to the western region (3.4 per 1,000 versus 3.1 per 1,000 in region west). Within the term group ( $\geq 37^{+0}$ weeks), the regional mortality difference was the largest for the group of births from women transferred from low risk to high risk during delivery (4.0 per 1,000 in north versus 2.6 per 1,000 in west). The perinatal mortality risk for term births from women selected as high risk at start of delivery was similar; in both northern and western regions 5.0 per 1,000.

\section{Discussion}

The perinatal mortality in the Netherlands for the period 2000-2004 shows regional variation, with an increased perinatal mortality in the rural northern region. The regional variation was present in both stillbirth and early neonatal mortality. The elevated risk in the northern region could not be explained by regional variation in demographic risk factors like maternal age, parity and ethnicity. Socio-economic status and urbanisation grade only explained a small part of the excess risk. Analyses focussed on clinical relevant subgroups showed regional differences were most prominent among births from $32^{+0}$ weeks gestation onwards and especially among term births from women transferred from low to high risk during delivery.

Data from a period of five years could be analyzed including 904,003 pregnancies in the Netherlands. The Netherlands Perinatal Registry contains the combined information on pregnancy, childbirth and the neonatal period derived from three separate registries that have recently been linked using probabilistic record linkage techniques. This enabled us to adjust for a combination of demographic, care related and socio-economic factors in relation to perinatal outcome $[16,20]$.

Data from general practitioners providing obstetric care were not available from the Netherlands perinatal registry. General practitioners more often provide obstetric care in rural areas, which are found in the northern region but also in the eastern and southern regions [21]. Overall the proportion of deliveries that took place under supervision of a general practitioner is estimated at $4 \%$. However over $99 \%$ of hospital deliveries were included and a woman is transferred to an obstetrician by the general practitioner in case of high risk. This is in accordance with the finding when the perinatal registry data were linked to civil registry data in a pilot study, more foetal deaths were registered in the perinatal registry, especially the very premature foetal deaths. Medical registries suffer from entry errors by professionals as any database. Limited entry options and data checks by professionals combined with validated linkage procedures $[15,22]$ have confined errors to a minimum. The current perinatal registry does not contain information on smoking (only reporting on heavy smoking with clear underestimation), food intake, folic acid intake, maternal education and body mass index (BMI),

Table 5: Prevalence and mortality risk for clinical risk groups by region.

\begin{tabular}{|c|c|c|c|c|c|c|c|c|}
\hline \multirow[b]{3}{*}{ Clinical risk groups } & \multicolumn{2}{|l|}{ North } & \multicolumn{2}{|l|}{ East } & \multicolumn{2}{|l|}{ West } & \multicolumn{2}{|l|}{ South } \\
\hline & Prev & Mortality risk & Prev & Mortality risk & Prev & Mortality risk & Prev & Mortality risk \\
\hline & $\%$ & $\%$ & $\%$ & $\%$ & $\%$ & $\%$ & $\%$ & $\%$ \\
\hline Very preterm births $<26^{+0}$ weeks & 0.27 & 937 & 0.28 & 947 & 0.31 & 928 & 0.32 & 951 \\
\hline Severe congenital anomalies & 0.80 & 204 & 0.81 & 163 & 0.81 & 147 & 1.02 & 105 \\
\hline Premature $26^{+0}-31^{+6}$ weeks & 0.89 & 233 & 0.74 & 248 & 0.76 & 237 & 0.72 & 214 \\
\hline Premature $32^{+0}-36^{+6}$ weeks & 5.14 & 33.6 & 4.77 & 30.2 & 4.75 & 29.6 & 5.26 & 26.6 \\
\hline Term $\geq 37^{+0}$ weeks & 92.89 & 3.4 & 93.40 & 3.2 & 93.38 & 3.1 & 92.69 & 2.8 \\
\hline Total & 100 & 11.2 & 100 & 10.2 & 100 & 10.1 & 100 & 9.6 \\
\hline
\end{tabular}

Prev $=$ prevalence 
factors which may (partly) explain the regional differences in perinatal mortality [23-25]. Additional adjustment for BMI and smoking on a province level for women in the reproductive age (data from Statistics Netherlands and STIVORO) did not change the elevated perinatal mortality risk in the northern region (data not shown). Risk factor behaviour in pregnancy is related to both socio-economic class and ethnicity $[26,27]$. After adjustment for these factors the risk status of the northern region remained high; therefore we believe that regional variation in unmeasured risk factors is unlikely to explain the observed differences in mortality in our adjusted models. One could challenge the use of the SES score on a neighbourhood level rather than on the individual level. However, previous research on socio-economic inequalities have demonstrated that this is a valid approach $[28,29]$.

This is the first time that regional differences in perinatal mortality were studied in the Netherlands using the national linked perinatal registry data on 904,003 pregnancies. Previous regional analyses were based on aggregate data on 11 provinces for the period 1979-1982 [6] and on 40 economic sub-regions for the period 19801984 [5], rather than on individual data. Treffers et al. found differences in the percentage of hospital deliveries (versus home deliveries) per province, but could not relate this to regional perinatal mortality rate [6]. We also found differences in hospital deliveries per region and found that the regional differences were most pronounced among term women transferred from low to high risk during delivery. Mackenbach et al. reported perinatal mortality rate to depend on mean income, part of the population living in a large municipality and the presence of a leveltwo hospital [5]. We applied individual demographic adjustment, and used more refined variables to account for SES and urbanisation. We had access to urbanisation and SES on the neighbourhood level based on postal code, which showed large variation between regions. Social factors have been reported as explanatory factors for perinatal mortality differences [12,13], however adjustment for SES and urbanisation only explained a small part of the excess risk in the northern region in our study. The presence of fewer hospitals in the northern region may have played a role. The differences in regional perinatal mortality are sizable, and consistent with recently observed mortality differences for other causes (cardiovascular, cancer) [30].

Regional variation in health outcomes can be caused by variation in incidence of complications and/or variation in prognosis. Health status of the women and preventive and obstetric care if applicable can influence incidence and prognosis. Both stillbirth and neonatal mortality were increased in the northern region, which indicates a role for factors common to both. Population composition factors and environmental risk factors, undetected by the direct and indirect adjustment factors can be present, but their presence is less likely given the adjustments. The analyses suggest that prevention and care factors may have played a role. Potential candidates are the following.

The uptake of prevention (general - smoking, specific folic acid, screening) may be less or the intensity or effectiveness of health services may be lower [31]. As differential access will have been partly covered by the adjustment factor urbanisation, explanations at the care level are more likely. The number of clinical facilities in the northern region is smaller, and only 1 tertiary centre is available. Perhaps intensity and quality of preventive and delivery care is less in areas with low population density $[32,33]$. The elevated mortality risk for children with congenital anomalies in the northern region (while prevalence was similar) might also point to differences in care shortly after birth. Late neonatal mortality (7-27 days) showed the same regional pattern, excluding mortality differences by different care management during the first week and subsequent delay of mortality. As an increased mortality risk in the northern region is present in both preterm and term births also differences in hospital supply services (obstetrical, neonatal) has to be considered, and delay due to the on average larger travelling distances in case of intended home births with an emerging risk requiring hospital admission. The group transferred from low to high risk during delivery is at higher risk for perinatal mortality than women who deliver under care of a midwife completely $[16,34]$. For term births the regional mortality differences were most pronounced in the group transferred from low to high risk during delivery, possibly indicating a role for travel distance. Further exploring the role of care factors rests on more detailed analysis of clinical risk groups for perinatal mortality and of stillbirth and neonatal mortality separately, but also on audit studies $[35,36]$. Audit studies could also provide information on causes of death, which is not registered in the current PRN registry. Against the background mortality observed in the other regions, the observed mortality in the northern region of 11.2 per 1,000 births and about 17,500 deliveries annually, this excess risk in the northern region accounts for about 19 deaths a year.

\section{Conclusion}

In conclusion, our study revealed persistent adverse perinatal outcome in the northern part of the Netherlands even after adjustment for demographic and socio-economic factors. Analysis of clinical risk groups showed perinatal mortality differences were most pronounced among children with severe congenital anomalies and among term births from women transferred from low to high risk during delivery. The results provide an incentive to explore the role of health care factors, both at the prenatal and delivery stage of care. 


\section{Competing interests}

The authors declare that they have no competing interests.

\section{Authors' contributions}

AR, MT, ME, JR and GB contributed to the conception and design of the study. JJE, HB and GR were involved in acquisition of the data. MT and AR conducted the analyses and MT drafted the manuscript. AR, GB, JR and ME provided advice on the analysis and interpretation of the data. All authors critically revised the draft versions and approved the final version of the manuscript.

\section{Acknowledgements}

We gratefully acknowledge the investment of numerous caregivers in the Netherlands providing the registry information. We thank The Netherlands Perinatal Registry http://www.perinatreg.nl for her permission to use the data.

\section{References}

I. Buitendijk S, Zeitlin J, Cuttini M, Langhoff-Roos J, Bottu J: Indicators of fetal and infant health outcomes. Eur J Obstet Gynecol Reprod Biol 2003, I I I(SuppI I):S66-S77.

2. Zeitlin J, Wildman K, Breart G, Alexander S, Barros H, Blondel B, et al.: PERISTAT: indicators for monitoring and evaluating perinatal health in Europe. Eur J Public Health 2003, 13:29-37.

3. Graafmans WC, Richardus JH, Macfarlane A, Rebagliato M, Blondel B, Verloove-Vanhorick SP, et al.: Comparability of published perinatal mortality rates in Western Europe: the quantitative impact of differences in gestational age and birthweight criteria. BJOG 200I, 108:1237-1245.

4. Mackenbach JP, Stronks K: A strategy for tackling health inequalities in the Netherlands. BM] 2002, 325: $1029-1032$.

5. Mackenbach JP, van Leengoed PL: [Regional differences in perinatal mortality: the relationship with various aspects of perinatal care]. Ned Tijdschr Geneeskd 1989, 133:1839-1844.

6. Treffers PE, Laan R: Regional perinatal mortality and regional hospitalization at delivery in The Netherlands. $\mathrm{Br} J$ Obstet Gynaecol 1986, 93:690-693.

7. de VE, Schouten LJ, Visser O, Eggermont AM, Coebergh JW: Rising trends in the incidence of and mortality from cutaneous melanoma in the Netherlands: a Northwest to Southeast gradient? Eur J Cancer 2003, 39:1439-1446.

8. Kunst AE, Looman CW, Mackenbach JP: Determinants of regional differences in lung cancer mortality in The Netherlands. Soc Sci Med 1993, 37:623-63I.

9. Mackenbach JP, Kunst AE, Looman CW: [Regional differences in mortality from ischemic heart disease]. Ned Tijdschr Geneeskd 1990, I34:596-60I.

10. Daltveit AK, Vollset SE, Irgens LM: Population density and perinatal mortality in Norway and Sweden 1975-1988. Scand J Public Health 1999, 27:213-219.

II. Gissler M, Keskimaki I, Teperi J, Jarvelin M, Hemminki E: Regional equity in childhood health - register-based follow-up of the Finnish 1987 birth cohort. Health Place 2000, 6:329-336.

12. Lauria L, De Stavola BL: A district-based analysis of stillbirth and infant mortality rates in Italy: 1989-93. Paediatr Perinat Epidemiol 2003, 17:22-32

13. Martuzzi M, Grundy C, Elliott P: Perinatal mortality in an English health region: geographical distribution and association with socio-economic factors. Paediatr Perinat Epidemiol 1998, 1 2:263-276.

14. Serenius F, Winbo I, Dahlquist G, Kallen B: Regional differences in stillbirth and neonatal death rate in Sweden with a cause-ofdeath specific analysis. Acta Paediatr 200I, 90:1062-1067.

15. Meray N, Reitsma JB, Ravelli AC, Bonsel GJ: Probabilistic record linkage is a valid and transparent tool to combine databases without a patient identification number. J Clin Epidemiol 2007, 60:883-891.

16. Ravelli AC, Eskes M, Tromp M, Huis AM, Steegers EAP, Tamminga P, et al.: [Perinatal mortality in the Netherlands 2000-2006; risk factors and risk selection]. Ned Tijdschr Geneeskd 2008, I 52:2728-2733.

17. World Health Organization: Definitions and Indicators in family planning maternal\&child health and reproductive health. WHO press. Geneva; 2001.

18. Sociaal en Cultureel Planbureau: Van hoog naar laag; van laag naar hoog. Rijswijk, Sociaal en Cultureel Planbureau; 1998.

19. Bleker OP, Hulst LAM van der, Eskes M, Bonsel GJ: Place of birth: evidence for best practice. In Recent advantage in Obstetrics and Gynaecology 23 Edited by: Bonnar J, Dunlop W. London: Royal Society of Medicine Press; 2005:77-100.

20. Ravelli AC], Tromp M, van Huis M, Steegers EAP, Tamminga P, Eskes $M$, et al.: Decreasing perinatal mortality in the Netherlands, 2000-2006: the impact of risk factors. Journal of Epidemiology and Community Health 2009 in press.

21. Wiegers T, Hingstman L: Inventarisatie 'verloskundig actieve huisartsen' Utrecht: Nivel; 1999.

22. Tromp M, Ravelli AC, Meray N, Reitsma JB, Bonsel GJ: An efficient validation method of probabilistic record linkage including readmissions and twins. Methods Inf Med 2008, 47:356-363.

23. Bhattacharya S, Campbell DM, Liston WA, Bhattacharya S: Effect of Body Mass Index on pregnancy outcomes in nulliparous women delivering singleton babies. BMC Public Health 2007, 7:168.

24. Devlieger H, Martens G, Bekaert A: Social inequalities in perinatal and infant mortality in the northern region of Belgium (the Flanders). Eur J Public Health 2005, 15:15-19.

25. Kallen $\mathrm{K}$ : The impact of maternal smoking during pregnancy on delivery outcome. Eur J Public Health 200I, I I:329-333.

26. Goedhart G, van EM, Wal MF van der, Bonsel G]: Ethnic differences in preterm birth and its subtypes: the effect of a cumulative risk profile. BJOG 2008, I I 5:710-719.

27. Mohsin M, Bauman AE: Socio-demographic factors associated with smoking and smoking cessation among 426,344 pregnant women in New South Wales, Australia. BMC Public Health 2005, 5: 138.

28. Bos V, Kunst AE, Garssen J, Mackenbach JP: Socioeconomic inequalities in mortality within ethnic groups in the Netherlands, 1995-2000. J Epidemiol Community Health 2005, 59:329-335.

29. Mackenbach JP, Stronks K, Kunst AE: The contribution of medical care to inequalities in health: differences between socio-economic groups in decline of mortality from conditions amenable to medical intervention. Soc Sci Med 1989, 29:369-376.

30. Zwakhals SLN, Giesberg H: Kanker totaal. In Volksgezondheid Toekomst Verkenning, Nationale Atlas Volksgezondheid Bilthoven: RIVM; 2006.

31. Raatikainen K, Heiskanen N, Heinonen S: Under-attending free antenatal care is associated with adverse pregnancy outcomes. BMC Public Health 2007, 7:268.

32. Moster D, Lie RT, Markestad T: Neonatal mortality rates in communities with small maternity units compared with those having larger maternity units. BJOG 200I, I08:904-909.

33. Phibbs CS, Bronstein JM, Buxton E, Phibbs RH: The effects of patient volume and level of care at the hospital of birth on neonatal mortality. JAMA 1996, 276: I054-1059.

34. Amelink-Verburg MP, Verloove-Vanhorick SP, Hakkenberg RM, Veldhuijzen IM, Bennebroek GJ, Buitendijk SE: Evaluation of 280,000 cases in Dutch midwifery practices: a descriptive study. BJOG 2008, II 5:570-578.

35. Merkus JM: [Perinatal mortality in The Netherlands: an audit is now more necessary than ever]. Ned Tijdschr Geneeskd 2008, I 52:603-605.

36. Richardus JH, Graafmans WC, Verloove-Vanhorick SP, Mackenbach JP: Differences in perinatal mortality and suboptimal care between 10 European regions: results of an international audit. BJOG 2003, I1 10:97-105.

\section{Pre-publication history}

The pre-publication history for this paper can be accessed here:

\section{http://www.biomedcentral.com/1471-2458/9/102/pre} pub 